\title{
Synthesis of Thinned Concentric Ring Array with Dipole Radiators Using Firefly Algorithm
}

\author{
T Pavani ${ }^{1}$, Dr. G.S.N. Raju ${ }^{2}$, Dr. P.V. Sridevi ${ }^{2}$ \\ ${ }^{I}$ Research Scholar, Department of ECE, Andhra University college of Engineering, Visakhapatnam, Andhra \\ Pradesh, India, \\ ${ }^{2}$ Professor, Department of ECE, Andhra University college of Engineering, Visakhapatnam, Andhra Pradesh, \\ India,
}

\begin{abstract}
The application of new metaheuristic approach, Firefly algorithm, for the thinning of large multiple Concentric Circular dipole arrays is presented. A nine-ring Uniform Circular antenna array with central element feeding is considered. To analyze the effect of thinning, optimization is carried out with and without pre fixing the percentage value of thinning. The performance of the array in terms of sidelobe level and beam width is discussed in four cases. The numerically simulated patterns are obtained and compared with those of concentric circular isotropic arrays.
\end{abstract}

Keywords: Concentric circular antenna array, Dipole elements, Firefly algorithm, sidelobe level, beam width

\section{Introduction}

Circular antenna has become very popular type antenna in mobile and communication applications. It has several advantages over other schemes such as azimuth scan capability and invariant beam pattern. The circular array is of high sidelobe geometry (approximately $8 \mathrm{~dB}$ below the main lobe). If the distance of array elements is decreased to reduce the sidelobes, the mutual coupling influence becomes more significant. For reducing high sidelobe levels, concentric arrays are utilized for smart antenna systems. A concentric circular antenna array (CCAA) is a planar array which consists of many concentric circular rings of different radii and a number of antenna elements located on the circumference of each ring. They are used to control the beam width, directivity and also for beam forming applications. Circular ring arrays are also favored in direction-of-arrival applications, since they provide almost invariant azimuth angle coverage [1].

The radiation pattern function of a concentric ring array has been expressed by Stearns and Stewart [2] as a truncated Fourier Bessel series and the non-uniform distribution of the rings has been approximated to a smaller number of equally spaced ones. Goto and Cheng showed that for a Taylor weighted ring array the maximum allowable inter-element spacing should be about four-tenths of a wavelength, if high sidelobes are to be avoided [3]. L. Biller used steepest descent iterative process to find out element weights and ring spacing to get lower sidelobe levels and control over beam width [4]. Huebner reduced the sidelobe levels for small concentric ring array by adjusting the ring radii using optimization technique [5]. B. P. Kumar also proposed optimum ring radii for generating lower sidelobes [6]. Dessouky showed that the existence of central element in case of concentric circular array of smaller innermost ring reduced the sidelobe levels significantly with minor increase in the beam width [7].

Uniformly excited and unequally spaced antenna arrays, have high directivity but they usually suffer from high sidelobe level. To reduce the SLL further, the array is made aperiodic by altering the positions of the antenna elements with all excitation amplitudes being uniform. Another possibility is to use unequally spaced array with radially tapered amplitude distribution. These processes are referred to as thinning. Thinning a large array for low sidelobes involves checking a rather large number of possibilities in order to find the best thinned aperture [8]. Element behavior in a thinned array is described in [9]. Thinning not only reducing the maximum sidelobe level, but it also decreases the manufacturing cost and weight of the arrays [10-11]. In the US military, it was used to design radar system with high performance [12].

Pathak and Mahanti proposed a technique based on modified particle swarm optimization combined with inverse fast Fourier transform for thinning a large linear array of parallel half-wave length dipole antennas to generate a pencil beam in the horizontal plane with minimum sidelobe level and fixed return loss [13]. Designing thinned linear arrays with practical radiating elements dipoles to achieve lowest sidelobe level have been discussed in [14]. Ghosh and Das proposed a technique based on optimization tool termed as DEGL for designing a thinned concentric planar circular antenna array of isotropic elements to generate a pencil beam [15]. In [16], CRPSO is adopted for the complex synthesis of three-ring CCAA with non-isotropic elements. Dib proposed the Teaching-learning-based optimization method in the optimal design of thinned CCAA [17].

However, most of the authors reported array thinning with uniform excitation amplitudes. Therefore in the present work, an attempt is made to design a thinned array with tapered amplitude distribution for sidelobe 
reduction. The half wavelength dipole antenna is considered as radiating element since it is the most widely used type of antenna. A new population based optimization method Firefly algorithm is employed for thinning a concentric circular dipole array antenna so as to reduce overall design cost of CCAA. Firefly algorithm (FA) is a novel metaheuristic which mimics flashing behavior of light bugs [18]. Four examples are considered: first case optimizes the position of the turned on elements of the uniformly excited array and null to null beam width is kept within $14.8^{0}$. Second designing instance calculates the nonuniform excitations as well as turned on elements for the same beam width. The same case is again repeated in the third example for a wider null to null beam width limited up to $20^{\circ}$. The synthesis of CCAA with pre fixed thinning percentage is carried out in the last instance while null to null beamwidth not more than $14.8^{0}$.

The rest of the paper is organized as follows: In section 2, Uniform concentric circular array geometry and mathematical formulation of the array factor is presented. Moreover cost function is given. A brief description of Firefly algorithm is given in section 3. Based on these models, numerical results are provided in section 4 and finally the paper is concluded in section 5 .

\section{Thinned array design}

A nine-ring uniform concentric circular dipole array with $\mathrm{N}_{\mathrm{m}}$ equally spaced elements along the circle of radius $r_{m}$ is shown in Figure 1 [19]. If all the elements are assumed to be isotropic sources, the radiation pattern of this array can be written in terms of its array factor only. But the elements considered in this paper are dipole radiators. When the actual elements are dipoles, the total field can be formed by multiplying the array factor of the isotropic sources with the field of a single element. The far field radiation pattern of the concentric dipole ring array with single element at the centre is then given by

$$
\mathrm{F}(\theta)=\operatorname{EP}(\theta) * \mathrm{~A}_{\mathrm{F}}(\theta)
$$

Where $\operatorname{EP}(\theta)$ gives the element pattern while $\mathrm{A}_{\mathrm{F}}(\theta)$ is the array factor of the CCAA.

The dipole element pattern is given by [20]

$$
\begin{aligned}
& \mathrm{EP}(\theta)=\left[\frac{\cos (\mathrm{kL} \cos \theta)-\cos \mathrm{kL}}{\sin \theta}\right] \\
& A_{F}(\theta)=1+\sum_{m=1}^{9} \sum_{n=1}^{N_{m}} I_{m n} \exp \left[j k r_{m} \cos \left(\theta-\phi_{m n}\right)-\sin \theta_{o} \cos \left(\phi_{o}-\phi_{m n}\right)\right] \\
& \mathrm{r}_{\mathrm{m}}=\mathrm{N}_{\mathrm{m}} \lambda / 4 \pi \\
& \phi_{\mathrm{mn}}=2 \mathrm{n} \pi / \mathrm{N}_{\mathrm{m}}
\end{aligned}
$$

Here,

$\mathrm{k}=2 \pi / \lambda=$ Wave number,

$\theta=$ Elevation angle measured between the positive $\mathrm{z}$-axis and the point of far field,

$\lambda=$ signal wavelength,

$\varphi=$ azimuth angle measured between the positive $\mathrm{x}$-axis and the projection of the far field point in the $\mathrm{x}-\mathrm{y}$ plane.

$\theta_{\mathrm{o}}, \varphi_{\mathrm{o}}$ represents direction at which main beam achieves its maximum.

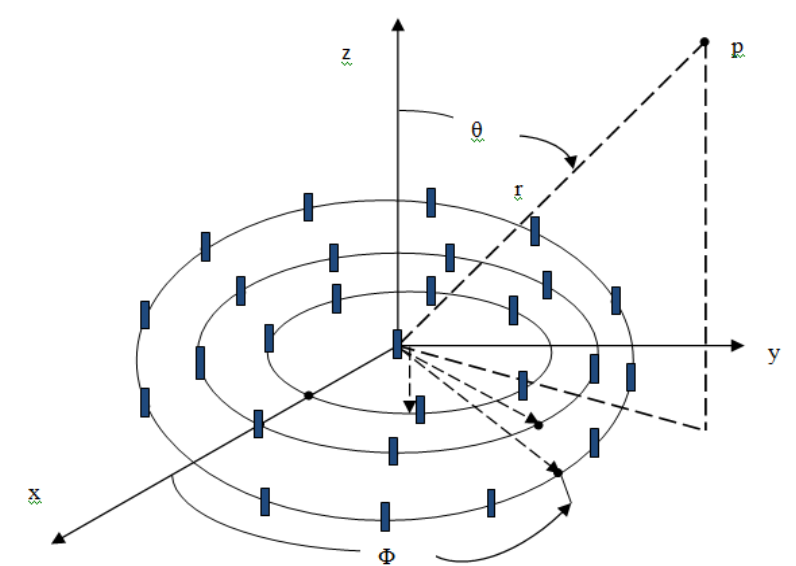

Fig 1. Geometry of a concentric circular array (CCAA). 
The Normalized power patterns in $\mathrm{dB}$ can be expressed as

$$
\mathrm{P}(\theta)=20 \log _{10}\left[\frac{|\mathrm{F}(\theta)|}{\left.|| \mathrm{F}(\theta)\right|_{\max } \mid}\right]
$$

The goal of optimization task in the four antenna designing problems is to minimize the maximum SLL subjected to numerous designing constraints. Uniform excitation is used in the first problem where remaining three are nonuniformly excited. The first three design instances are synthesized for different values of null to null beam width as optimization constraint. However, last problem is synthesized for a fixed level of thinning percentage and null to null beam width. By considering all the above, the cost functions are formulated as follows.

$$
\begin{aligned}
\cos \mathrm{t} 1 & = \begin{cases}\max (\mathrm{SLL}) & \text { subject to } \mathrm{F}_{\mathrm{o}} \leq \mathrm{F}_{\mathrm{d}} \\
10^{2} & \text { otherwise }\end{cases} \\
\cos \mathrm{t} 2 & =\left\{\begin{array}{ll}
\max (\mathrm{SLL})+\left(\mathrm{Th}_{\mathrm{o}}-\mathrm{Th}_{\mathrm{d}}\right)^{2} \\
10^{2} & \text { otherwise }
\end{array} \text { subject to } \mathrm{F}_{\mathrm{o}} \leq \mathrm{F}_{\mathrm{d}}\right.
\end{aligned}
$$

$F_{o}$ and $F_{d}$ are the obtained and desired values of the first null beamwidth. $T h_{o}$ and $T h_{d}$ are the obtained and desired values of percentage of thinning. Thus, for the design of thinned CCAA with minimum SLL, the optimization problem is to search for the current amplitudes that are turned ON or OFF that accomplish this cost function.

\section{Firefly algorithm}

Firefly algorithm (FA) is the one of the latest swarm intelligence metaheuristics. In which the search algorithm is inspired by the flashing behavior of fireflies and the phenomenon of bioluminescent communication. The flashing light helps fireflies for finding mates, attracting their potential prey and protecting themselves from their predators. The main algorithm's principle is that each firefly moves towards brighter and more attractive locations by the flashing light intensity that associated with the objective function of problem is considered [21].

The development of firefly algorithm was based on three idealized rules:

- $\quad$ Each firefly attracts all other fireflies with weaker flashes regardless of their sex.

- Attractiveness is proportional to their brightness and decreases as the distance among them increases.

- The brightness of a firefly is affected or determined by the distribution of the objective function.

For a maximization problem, brightness can simply be proportional to the value of the cost function. Other forms of brightness can be defined in a similar way to the fitness function in genetic algorithm. The basic steps of the FA can be summarized as the pseudo code.

Begin

1. Initialize algorithm parameters max generation, $\alpha, \beta_{0}, \gamma$

2. Create initial population of $\mathrm{n}$ fireflies $\mathrm{x}=\left(\mathrm{x}_{1}, \mathrm{x}_{2}, \mathrm{x}_{3} \ldots \mathrm{x}_{\mathrm{D}}\right)^{\mathrm{T}}$ within $\mathrm{D}$ dimensional search space

3. Objective function $\mathrm{f}(\mathrm{x}), \mathrm{x}=\left(\mathrm{x}_{1}, \mathrm{x}_{2}, \mathrm{x}_{3}, \ldots \ldots \ldots, \mathrm{x}_{\mathrm{D}}\right)^{\mathrm{T}}$

4. Determine $\mathrm{I}_{\mathrm{i}}$ at $\mathrm{x}_{\mathrm{i}}$ determined by $\mathrm{f}\left(\mathrm{x}_{\mathrm{i}}\right)$

5. While $(\mathrm{t}<$ maxgeneration)

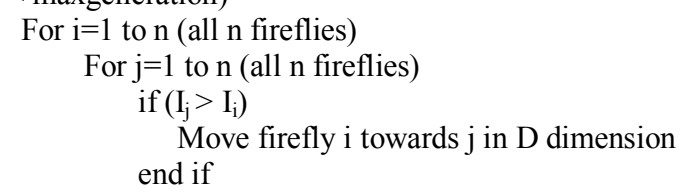

Evaluate new solutions and update light intensity end for $\mathrm{j}$ end for I

Rank the fireflies and find the current best end while

Post process results and visualization

End procedure 
In this algorithm, each firefly has a location $\mathrm{x}=\left(\mathrm{x}_{1}, \mathrm{x}_{2}, \mathrm{x}_{3} \ldots \mathrm{x}_{\mathrm{D}}\right)^{\mathrm{T}}$ in a D-dimensional search space. Light intensity $\mathrm{I}(\mathrm{x})$ (or) attractiveness $\beta(\mathrm{x})$, which are proportional to an objective function $\mathrm{f}(\mathrm{x})$ [16].

In order to design FA, two important issues need to be defined: (a). The variation of light intensity, (b). Formulation of attractiveness. In the FA, the light intensity I of a firefly is proportional to the value of fitness function $\mathrm{I}(\mathrm{s}) \propto \mathrm{f}(\mathrm{s})$, where $\mathrm{s}$ denotes solution.

The light intensity I(r) varies according to the following equation:

$$
\mathrm{I}(\mathrm{r})=\mathrm{I}_{\mathrm{o}} \exp \left(-\gamma \mathrm{r}^{2}\right)
$$

Where $\mathrm{I}_{0}$ represents the light intensity of source and $\gamma$ is the light absorption coefficient which can be taken as constant.

The firefly's attractiveness is proportional to the light intensity seen by adjacent fireflies. Therefore, the attractiveness $\beta$ of a firefly is defined by

$$
\beta(\mathrm{r})=\beta_{\mathrm{o}} * \exp \left(-\gamma \mathrm{r}_{\mathrm{ij}}^{2}\right)
$$

Where $\beta_{\mathrm{o}}$ is a constant and presents the attractiveness at $\gamma=0$.

The distance between any two fireflies $x_{i}$ and $x_{j}$ are expressed as the Cartesian distance

$$
\gamma_{i j}=\left|x_{i}-x_{j}\right|=\sqrt{\sum_{k=1}^{n}\left(x_{i j}-x_{j k}\right)^{2}}
$$

The movement of a firefly $\mathrm{i}$ is attracted to another brighter firefly $\mathrm{j}$ is given by the following equation:

$$
\mathrm{x}_{\mathrm{i}}=\mathrm{x}_{\mathrm{i}}+\beta_{\mathrm{o}} * \exp \left(-\gamma \mathrm{r}_{\mathrm{ij}}^{2}\right) *\left(\mathrm{x}_{\mathrm{j}}-\mathrm{x}_{\mathrm{i}}\right)+\alpha *(\text { rand }-1 / 2)
$$

In the above, the first term is the current position of $i^{\text {th }}$ firefly. The second term is due to the attraction to another more attractive firefly and in the third term $\alpha$ is randomization parameter controlling the step size. Here, rand is a random number generator uniformly distributed in between 0 and 1 .

The brightness and the attractiveness of each firefly are calculated at each iterative step. Based on these values the positions of the fireflies are updated. All fireflies converge to the best possible position on the search space after a sufficient amount of iterations.

\section{Results}

A planar array of 9 concentric circular rings with center element is considered. The radii of the rings are $r_{m}=m \lambda / 2$ ( $m^{\text {th }}$ ring) and the inter element spacing of elements in each ring is kept at $d_{m}=0.5 \lambda$. The number of elements in the $\mathrm{m}^{\text {th }}$ ring is found out by rounding off the values of $\mathrm{N}_{\mathrm{m}}=2 \pi \mathrm{r}_{\mathrm{m}} / \mathrm{d}_{\mathrm{m}}$ and the total number of elements becomes 279 . For such a fully populated and uniformly excited array, the maximum sidelobe level is calculated to be $-17.4 \mathrm{~dB}$ and first null beam width (FNBW) is $14.8^{0}$. FA is applied to find the optimal set of ON and OFF elements that will generate pencil beam. Four instantiations of the design problem are considered.

In the first example, the uniformly excited array used $18.1 \%$ thinning to reduce the SLL to $-23.7 \mathrm{~dB}$ null to null beam width is not allowed to exceed the value of $14.8^{0}$. Distribution of turned ON and turned OFF elements are given in Table 1. The normalized power patterns of a thinned 9-ring Isotropic and dipole CCA are presented in Figure 2.

In the second example, FA is applied to compute the distributions of turned ON and turned OFF elements along with the nonuniform excitations applied on turned $\mathrm{ON}$ elements. Use of nonuniform excitations reduced the SLL to $-24.16 \mathrm{~dB}$ for same beam width using $20.95 \%$ thinning. Distribution of turned ON and turned OFF elements and nonuniform amplitude excitations are given in Table 2 and 3 respectively. The normalized power patterns of a thinned 9-ring isotropic and dipole CCA are shown in Figure 2.

In the next example, FA is applied for the same design instances. However, FNBW is allowed to increase up to $20^{\circ}$. Radiation patterns are generated with SLL equal to $-33.50 \mathrm{~dB}$ and FNBW $=19.98^{0}$. The percentage of thinning obtained in this case is $45.87 \%$. Distribution of turned ON and turned OFF elements and nonuniform amplitude excitations are given in Table 4 and 5 respectively. Figure 5 gives the normalized power patterns of a thinned 9-ring Isotropic and dipole CCA.

Finally the array is optimally thinned to minimize SLL for FNBW $=14.8^{0}$. Desired value of thinning is fixed at $50 \%$. FA is applied to compute the distributions of turned ON and turned OFF elements along with the nonuniform excitations applied on turned ON elements. Distribution of turned ON and turned OFF elements and nonuniform amplitude excitations are given in Table 6 and 7 respectively. Figure 6 presents the normalized power patterns with $\mathrm{FNBW}=14.8^{0}$. The results obtained from the four designing instances are given in table 8 . 


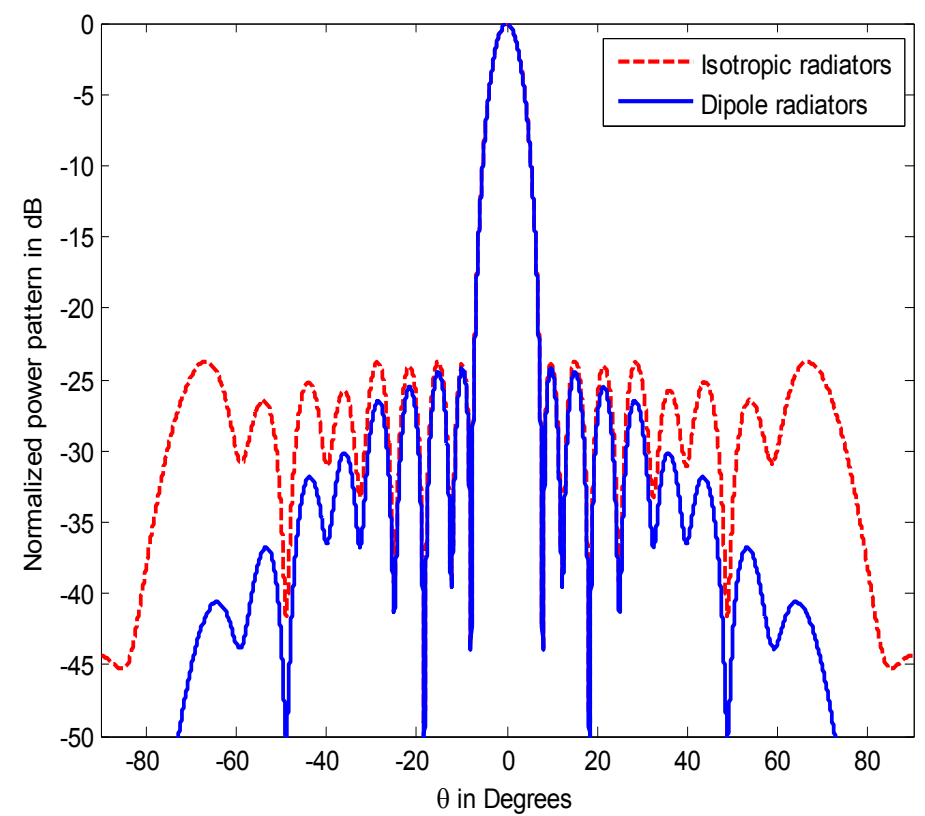

Fig 1.Normalized power patterns of a thinned 9-ring Isotropic and Dipole CCAA with FNBW=14.8

Table 1. Distribution of turned on and turned off elements of the uniformly excited thinned 9-ring Isotropic and Dipole CCAA with FNBW=14.8 .

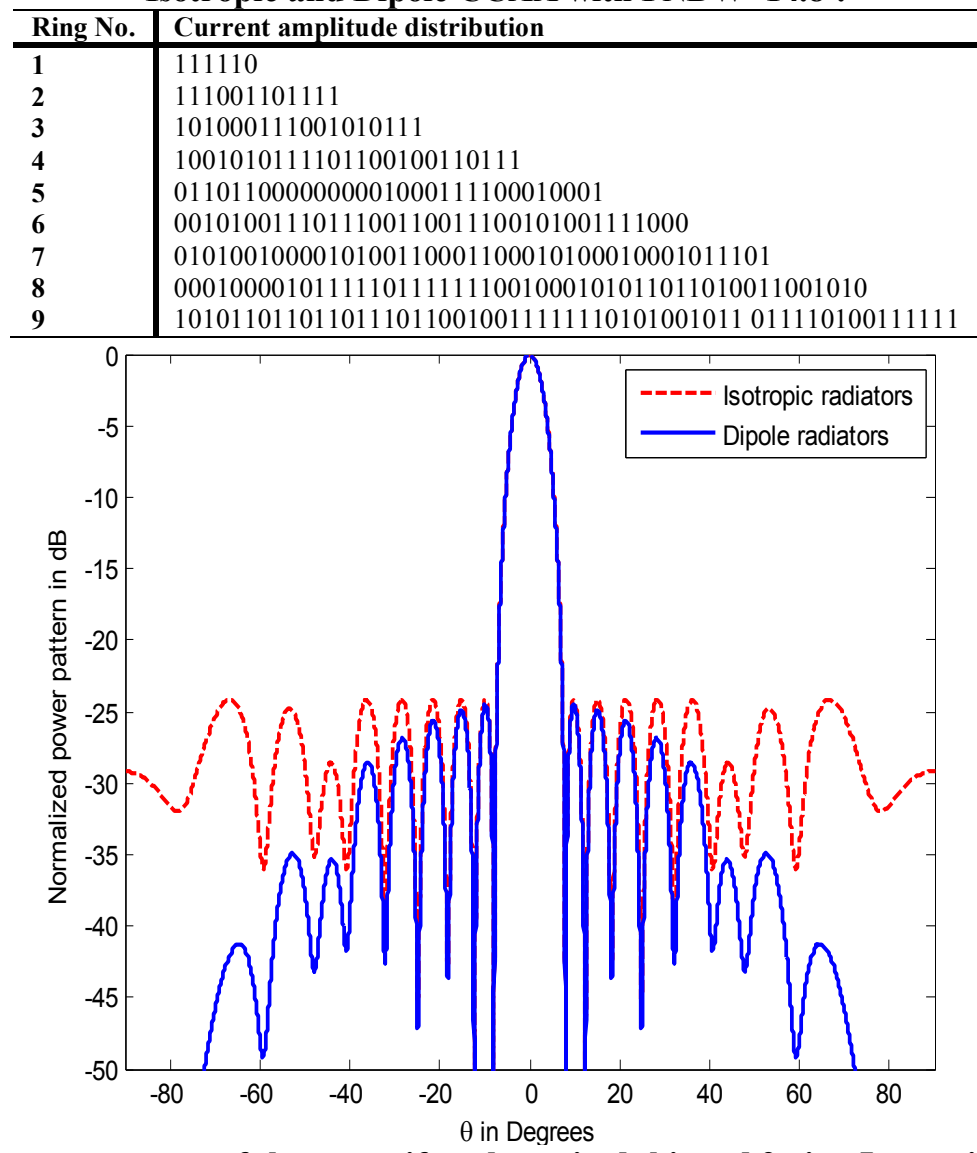

Fig 2.Normalized power patterns of the nonuniformly excited thinned 9-ring Isotropic and Dipole CCAA with $F N B W=14.8^{0}$. 
Table 2. Distribution of turned on and turned off elements of the nonuniformly excited thinned 9-ring CCAA with FNBW=14.8 ${ }^{\circ}$.

\begin{tabular}{l|l}
\hline Ring No. & Current amplitude distribution \\
\hline $\mathbf{1}$ & 111001 \\
$\mathbf{2}$ & 011001100111 \\
$\mathbf{3}$ & 111001111001100100 \\
$\mathbf{4}$ & 0010110010111000101111010 \\
$\mathbf{5}$ & 1010010110110100101111000111011 \\
$\mathbf{6}$ & 0111011000001101010011001101111110110 \\
$\mathbf{7}$ & 1111000000110010100010111110111111011100101 \\
$\mathbf{8}$ & 00100011100011011100010101000010001101100001100100 \\
$\mathbf{9}$ & 11100100001011110010011011111100111001011110110110111011 \\
\hline
\end{tabular}

Table 3. Nonuniform amplitude distribution of the thinned 9-ring array with FNBW=14.8 .

\begin{tabular}{l|l}
\hline $\begin{array}{l}\text { Ring } \\
\text { No. }\end{array}$ & Current amplitude distribution \\
\hline $\mathbf{1}$ & $0.5373,0.9138,0.9119,0,0,0.5158$ \\
$\mathbf{2}$ & $0,0.9630,0.8594,0,0,0.7191,0.6672,0,0,0.8421,0.7683,0.9722$ \\
$\mathbf{3}$ & $0.7696,0.8191,0.7682,0,0,0.9462,0.5425,0.5589,0.6638,0,0,0.7604,0.7415,0,0,0.8210,0,0$ \\
$\mathbf{4}$ & $0,0,0.8622,0,0.6159,0.8871,0,0,0.9930,0,0.9550,0.9706,0.7993,0,0,0,0.5251,0,0.9225,0.7377,0.8574,0.8456,0,0.6846,0$ \\
$\mathbf{5}$ & $0.5982,0,0.5349,0,0,0.7665,0,0.9974,0.7085,0,0.9165,0.6014,0,0.5211,0,0,0.7765,0,0.7061,0.6514,0.8116$ \\
& $0.5073,0,0,0,0.6350,0.9625,0.7894,0,0.5235,0.8026$ \\
$\mathbf{6}$ & $0,0.5515,0.8050,0.5082,0,0.8831,0.6434,0,0,0,0,0,0.5634,0.9348,0,0.5325,0,0.8654,0,0,0.9996,0.6312,0,0$ \\
& $0.9923,0.9783,0,0.8004,0.6249,0.8103,0.9960,0.8805,0.8200,0,0.6253,0.7705,0$ \\
$\mathbf{7}$ & $0.8665,0.7103,0.8089,0.6129,0,0,0,0,0,0,0.5772,0.5729,0,0,0.7096,0,0.9555,0,0,0,0.6942,0,0.6679,0.9045$ \\
& $0.5336,0.6721,0.6519,0,0.9812,0.7586,0.5460,0.8810,0.5247,0.9737,0,0.5603,0.8906,0.9991,0,0,0.5209,0,0.5860$ \\
$\mathbf{8}$ & $0,0,0.8725,0,0,0,0.5158,0.5506,0.9872,0,0,0,0.6074,0.5649,0,0.7513,0.9325,0.6121,0,0,0,0.8214,0,0.8087,0$ \\
$\mathbf{9}$ & $0.8518,0,0,0,0,0.5955,0,0,0,0.8584,0.5159,0,0.6837,0.8241,0,0,0,0,0.6403,0.5994,0,0,0.9153,0,0$ \\
& $0.7074,0.9773,0.9907,0,0,0.7690,0,0,0,0,0.6355,0,0.5686,0.5287,0.9940,0.5766,0,0,0.6360,0,0,0.9225$, \\
& $0.5158,0,0.8758,0.9878,0.7110,0.8411,0.7133,0.7747,0,0,0.7620,0.9556,0.6367,0,0,0.8474,0,0.5891,0.5451,0.8128,0.5410,0,0.71$ \\
\hline
\end{tabular}

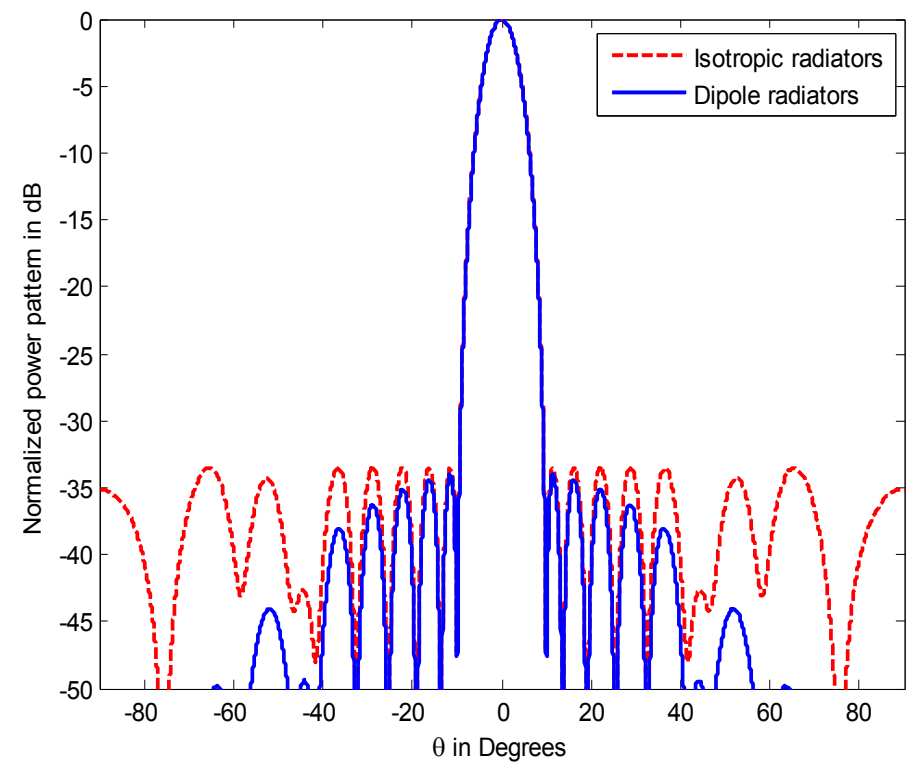

Fig 3.Normalized power patterns of the nonuniformly excited thinned 9-ring Isotropic and Dipole CCAA with $\mathrm{FNBW}=\mathbf{2 0}{ }^{\circ}$.

Table 4. Distribution of turned on and turned off elements of the nonuniformly excited thinned 9-ring CCAA with $\mathrm{FNBW}=\mathbf{2 0} 0^{\circ}$.

\begin{tabular}{l|l}
\hline Ring No. & Current amplitude distribution \\
\hline $\mathbf{1}$ & 111011 \\
$\mathbf{2}$ & 111100010011 \\
$\mathbf{3}$ & 001001011010111111 \\
$\mathbf{4}$ & 1101111111010001011101101 \\
$\mathbf{5}$ & 0101101100010110011110101100111 \\
$\mathbf{6}$ & 0101111001110000000010100111111110001 \\
$\mathbf{7}$ & 0100100111011000011000000111011100110010110 \\
$\mathbf{8}$ & 11000100000101111010111000000000110111010111000100 \\
$\mathbf{9}$ & 10001101110110101110100100101001011111111010010011000011 \\
\hline
\end{tabular}


Table 5. Nonuniform amplitude distribution of the thinned 9-ring array with $\mathrm{FNBW}=\mathbf{2 0} 0^{\circ}$.

\begin{tabular}{|c|c|}
\hline $\begin{array}{l}\text { Ring } \\
\text { No. }\end{array}$ & Current amplitude distribution \\
\hline 1 & $0.5385,0.6001,0.5145,0,0.8422,0.5682$ \\
\hline 2 & $0.5770,0.9655,0.7417,0.5241,0,0,0,0.9621,0,0,0.6344,0.9456$ \\
\hline 3 & $0,0,0.6104,0,0,0.9413,0,0.5678,0.9209,0,0.7089,0,0.6925,0.9217,0.9005,0.7583,0.7063,0.8992$ \\
\hline 4 & $\begin{array}{l}0.5850,0.9550,0,0.6774,0.7060,0.9945,0.5500,0.9300,0.7831,0.9698,0,0.5872,0,0,0,0.9693,0,0.6654,0.6161 \\
0.9040,0,0.9470,0.9215,0,0.6321\end{array}$ \\
\hline 5 & $\begin{array}{l}0,0.8269,0,0.5563,0.9502,0,0.6436,0.6468,0,0,0,0.9461,0,0.6760,0.9621,0,0,0.5227,0.6197,0.6553,0.8314,0, \\
0.6070,0,0.8692,0.7371,0,0,0.5855,0.8525,0.8593\end{array}$ \\
\hline 6 & $\begin{array}{l}0,0.6236,0,0.7118,0.6813,0.7542,0.9511,0,0,0.7701,0.9285,0.9358,0,0,0,0,0,0,0,0,0.7351,0,0.7115,0,0, \\
0.5937,0.8703,0.7985,0.6087,0.9645,0.8449,0.7627,0.7004,0,0,0,0.8459\end{array}$ \\
\hline 7 & $\begin{array}{l}0,0.8336,0,0,0.6352,0,0,0.7194,0.8973,0.6554,0,0.6805,0.8284,0,0,0,0,0.9337,0.8204,0,0,0,0,0,0,0.8551, \\
0.8681,0.7946,0,0.6572,0.7570,0.8139,0,0,0.6132,0.6208,0,0,0.9783,0,0.9239,0.5888,0\end{array}$ \\
\hline 8 & $\begin{array}{l}0.8136,0.6559,0,0,0,0.8128,0,0,0,0,0,0.6744,0,0.9637,0.8041,0.5589,0.8625,0,0.9785,0,0.8249,0.8103, \\
0.6663,0,0,0,0,0,0,0,0,0,0.6597,0.5135,0,0.6536,0.6694,0.9406,0,0.5228,0,0.5498,0.8126,0.6915,0,0,0 \\
0.8136,0,0\end{array}$ \\
\hline 9 & $\begin{array}{l}0.9928,0,0,0,0.7072,0.5098,0,0.5849,0.5017,0.9342,0,0.5502,0.7149,0,0.9794,0,0.7156,0.5829,0.5815,0, \\
0.6399,0,0,0.8488,0,0,0.6500,0,0.7382,0,0,0.5871,0,0.8606,0.7825,0.7810,0.5297,0.9717,0.8395,0.7844 \\
0.7091,0,0.8760,0,0,0.8257,0,0,0.5592,0.7020,0,0,0,0,0.6613,0.6354\end{array}$ \\
\hline
\end{tabular}

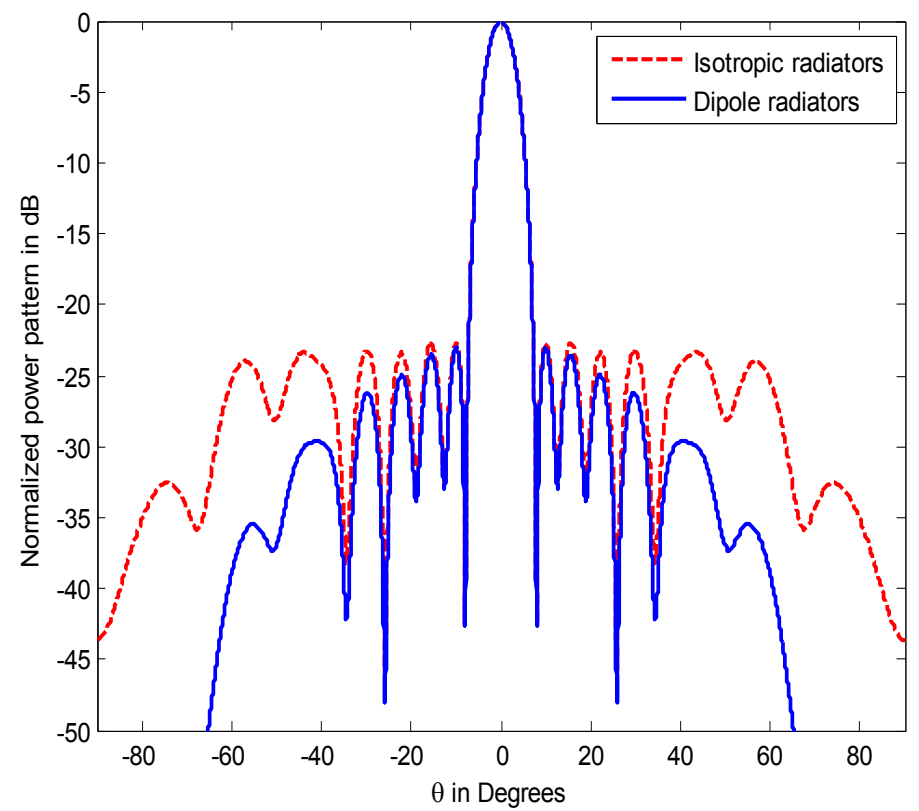

Fig 4.Normalized power patterns of the nonuniformly excited 50\% thinned 9-ring Isotropic and Dipole CCAA with FNBW=14.8 ${ }^{\circ}$.

Table 6. Distribution of turned on and turned off elements of the nonuniformly excited 50\% thinned 9ring CCAA with FNBW=14.8 ${ }^{0}$.

\begin{tabular}{l|l}
\hline Ring No. & Current amplitude distribution \\
\hline $\mathbf{1}$ & 000101 \\
$\mathbf{2}$ & 110111100010 \\
$\mathbf{3}$ & 101111011000010110 \\
$\mathbf{4}$ & 1010010110101010110010001 \\
$\mathbf{5}$ & 1101110110001000010110011101010 \\
$\mathbf{6}$ & 0110000010001000000100010011111100110 \\
$\mathbf{7}$ & 0000100001010010100011000010010100001010000 \\
$\mathbf{8}$ & 10100010100000101111110000111001011001000000000100 \\
$\mathbf{9}$ & 00101010001100100110110101010110001100101101110011110011 \\
\hline
\end{tabular}

Table 7. Nonuniform amplitude distribution of the $50 \%$ thinned 9-ring array with FNBW=14.8 0

\begin{tabular}{l|l}
\hline $\begin{array}{l}\text { Ring } \\
\text { No. }\end{array}$ & Current amplitude distribution \\
\hline $\mathbf{1}$ & $0,0,0,0.5641,0,0.5819$ \\
$\mathbf{2}$ & $0.5900,0.6470,0,0.5428,0.6466,0.6093,0.6359,0,0,0,0.6169,0$ \\
$\mathbf{3}$ & $0.6098,0,0.5612,0.6938,0.5981,0.6237,0,0.5868,0.6853,0,0,0,0,0.5502,0,0.5598,0.5897,0$ \\
$\mathbf{4}$ & $0.6114,0,0.5288,0,0,0.6037,0,0.6993,0.5806,0,0.6402,0,0.6680,0,0.5925,0,0.5314,0.5304,0,0,0.5929,0,0,0$ \\
& 0.8070
\end{tabular}




\begin{tabular}{|c|c|}
\hline 5 & $\begin{array}{l}0.6582,0.5348,0,0.6619,0.6220,0.5148,0,0.6207,0.6462,0,0,0,0.5503,0,0,0,0,0.7732,0,0.5218,0.6471,0,0, \\
0.6076,0.7532,0.5314,0,0.7660,0,0.5371,0\end{array}$ \\
\hline 6 & $\begin{array}{l}0,0.5136,0.7679,0,0,0,0,0,0.6927,0,0,0,0.5485,0,0,0,0,0,0,0.8463,0,0,0,0.5182,0,0,0.6656,0.5752,0.5590 \\
0.5432,0.6292,0.5168,0,0,0.6797,0.5829,0\end{array}$ \\
\hline 7 & $\begin{array}{l}0,0,0,0,0.7019,0,0,0,0,0.5657,0,0.6324,0,0,0.6162,0,0.6039,0,0,0,0.5238,0.5233,0,0,0,0,0.6072,0,0,0.5406, \\
0,0.6461,0,0,0,0,0.8450,0,0.6948,0,0,0,0\end{array}$ \\
\hline 8 & $\begin{array}{l}0.6160,0,0.5444,0,0,0,0.7752,0,0.5631,0,0,0,0,0,0.5813,0,0.5277,0.6526,0.5144,0.5926,0.5347,0.6817,0,0,0 \\
0,0.5253,0.8090,0.6841,0,0,0.6372,0,0.6108,0.6497,0,0,0.5428,0,0,0,0,0,0,0,0,0,0.7010,0,0\end{array}$ \\
\hline 9 & $\begin{array}{l}0,0,0.7004,0,0.6322,0,0.6033,0,0,0,0.5891,0.7063,0,0,0.6450,0,0,0.5371,0.5878,0,0.5244,0.6496,0,0.6397,0 \\
0.5503,0,0.6152,0,0.5706,0.8675,0,0,0,0.5539,0.6364,0,0,0.5995,0,0.6316,0.6775,0,0.6450,0.6089,0.6134, \\
0,0,0.7823,0.5618,0.7282,0.6289,0,0,0.5380,0.7603\end{array}$ \\
\hline
\end{tabular}

Table 8. Results obtained using thinned 9-ring array.

\begin{tabular}{|c|c|c|c|c|}
\hline \multirow{2}{*}{$\begin{array}{c}\text { Design } \\
\text { parameters }\end{array}$} & Example 1 & Example 2 & Example 3 & Example 4 \\
\hline & $\begin{array}{l}\text { Thinned arrays with unity } \\
\text { excitation and fixed null } \\
\text { to null beam width }\end{array}$ & $\begin{array}{l}\text { Thinned arrays with tapering } \\
\text { excitation amplitude and } \\
\text { fixed null to null beam width }\end{array}$ & $\begin{array}{l}\text { Thinned arrays with tapering } \\
\text { excitation amplitude and } \\
\text { wider null to null beam width }\end{array}$ & $\begin{array}{l}50 \% \text { Thinned arrays with } \\
\text { tapering excitation } \\
\text { amplitude and fixed null } \\
\text { to null beam width }\end{array}$ \\
\hline $\begin{array}{l}\text { Percentage of } \\
\text { thinning }\end{array}$ & 18.90 & 20.95 & 45.87 & 56.63 \\
\hline $\operatorname{SLL}(\mathrm{dB})$ & -23.70 & -24.16 & -33.50 & -22.70 \\
\hline $\begin{array}{l}\text { Null to null } \\
\text { beam width }\end{array}$ & $14.98^{0}$ & $14.98^{0}$ & $19.98^{0}$ & $14.98^{0}$ \\
\hline
\end{tabular}

\section{Conclusion}

In this paper, the method of thinning of a concentric nine-ring array of isotropic and dipole elements using firefly algorithm to reduce sidelobe level for specific null to null beam width is described. Four design instances are presented in the paper with different objectives. It is evident from the results that use of nonuniform amplitude excitations in the thinned array reduces the SLL more effectively. It is also observed that increasing null to null beam width can significantly enhance the sidelobe level. Moreover, prefixing the percentage of thinning at a higher value will cut down the cost of designing the arrays significantly. The method can be extended for thinning of other geometries and constraints.

[1] Lal Chand Godara, Smart Antennas, CRC press LLC, 2004

\section{References}

[2] C. Stearns, and A. Stewart, An investigation of concentric ring antennas with low sidelobes, IEEE transactions on Antennas and Propagation, Vol. 13, No. 6, 1965, pp. 856-863.

[3] N. Goto, D. K. Cheng, on the synthesis of concentric-ring array, Proceedings of IEEE, Vol. 58, No. 5, 1970, pp. 839-840.

[4] L. Biller, G. Friedman, Optimization of radiation patterns for an array of concentric ring sources, IEEE transactions on Audio and Electroacoustics, Vol. 21, No. 1, 1973, pp. 57-61.

[5] D. Huebner, Design and Optimization of low sidelobe circular ring array by element radius optimization, IEEE transactions on Antennas and Propagation, Vol. 16, 1978, pp. 455-458.

[6] B. P. Kumar, G. R. Branner, Design and Optimization of small concentric ring array, Antennas and propagation society International Symposium, IEEE, Vol. 3, 1999, pp. 62032-2035.

[7] M. Dessouky, H. Sharshar and Y. Albagory, Efficient sidelobe reduction technique for small-sized concentric circular array, Progress in Electromagnetics Research, Vol. 65, 2006, pp. 187-200.

[8] R. L. Haupt, Optimized element spacing for low sidelobe concentric ring array, IEEE transactions on Antenna and propagation, Vol. 56, No. 1, 2008, pp. 266-268.

[9] L. Schwartzman, Element behavior in a thinned array, IEEE transactions on Antenna and propagation, Vol. 15, No. 7, 1967, pp. 571-572.

[10] R. L. Haupt, Thinned concentric ring arrays, Antennas and propagation society International Symposium, AP-S, IEEE, 2008, pp. 14.

[11] R. L. Haupt, Inter leaved thinned linear arrays, IEEE transactions on Antenna and propagation, Vol. 53, No. 9, 2005 , pp. $2858-2864$.

[12] P. J. Kahrilas, HAPDAR-An operational phased array radar, proc IEEE, Vol. 56, No. 11, 1968, pp. 1967-1975.

[13] N. Pathak, B. Basu and G. K. Mahanti, Combination of Inverse Fast Fourier transform and Modified Particle swarm optimization for synthesis of thinned mutually coupled linear array of parallel Half-wave length dipole antennas, Progress in Electromagnetics Research M, Vol. 16, 2011, pp. 105-115.

[14] V. Rajya lakshmi and G. S. N. Raju, Optimization of thinned dipole arrays using Genetic algorithm, International journal of Engineering and technology, Vol. 3, No. 6, 2011.

[15] P. Ghosh and S. Das, Synthesis of thinned planar concentric circular antenna arrays-A Differential evolutionary approach, Progress in Electromagnetics Research, Vol. 29, 2011, pp. 63-82.

[16] D. Mandal, R. Kar and S. P. Ghoshal, Improved particle swarm optimization based synthesis of concentric circular antenna array with Non-isotropic elements, International conference on Recent trends in information systems, 2011, pp. 105-110.

[17] N. Dib, A. Sharaqa, Synthesis of thinned concentric circular antenna array using Teaching-Learning-Based optimization, International journal of RF and Microwave Computer-aided Engineering, Vol. 24, No. 4, 2014.

[18] X. S. Yang, (2008): Nature inspired metaheuristic algorithms, First edition, Luniver press, UK, pp.79-86.

[19] M. Dessouky, H. Sharshar and Y. Albagory, Optimum normalized-Gaussian tapering window for sidelobe reduction in uniform concentric circular arrays, Progress in Electromagnetics Research, Vol. 69, 2007, pp. 35-46.

[20] G. S. N. Raju, Antennas and Propagation, Pearson Education, 2005. 
[21] L. Szymon, Z. Slawomir, Firefly algorithm for continuous constrained optimization tasks, lecture notes in computer science, Springer link, 5796, 2009, pp. 97-106.

\section{Author's Information}

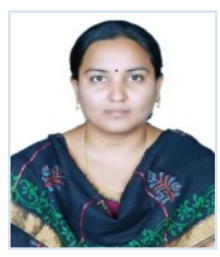

T. Pavani received her AMIE degree in Electronics and Communication Engineering in the year of 2006 from Institution of Engineers (INDIA) and Master of Technology in Radar and Microwave Engineering in 2009 from Andhra University College of Engineering (A). Currently, she is working towards her Ph.D. degree in the department of Electronics and Communication Engineering, Andhra University College of Engineering (A). Her Research interests include Microwave Antennas, EMI/EMC and Applications of Soft computing. She is a life member of Institution of Engineers and SEMCE (INDIA).

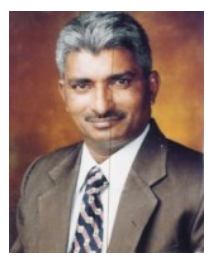

Dr. G.S.N. Raju received his B.E., M.E. with distinction and first rank from Andhra University and Ph.D. from IIT, Kharagpur. At present, he is the Vice - Chancellor of Andhra University and a Senior Professor in Electronics and Communication Engineering. He is in teaching and research for the last 30 years in Andhra University. He guided 28 Ph.D.s in the fields of Antennas, Electromagnetics, EMI/EMC and Microwave, Radar Communications, Electronic circuits. Published about 304 technical papers in National/ International Journals/ Conference Journals and transactions. He is the recipient of 'The State Best Teacher Award' from the Government of Andhra Pradesh in 1999, 'The Best Researcher Award' in 1994, 'Prof. Aiya Memorial National IETE Award' for his best Research guidance in 2008 and Dr. Sarvepalli Radhakrishnan Award for the Best Academician of the year 2007, He was a visiting Professor in the University of Paderborn and also in the University Karlsruhe, Germany in 1994. He held the positions of Principal, Andhra University College of Engineering (A), Visakhapatnam, Chief Editor of National Journal of Electromagnetic Compatibility. Prof. Raju has published five textbooks Antennas and Wave Propagation, Electromagnetic Field Theory and Transmission Lines, Electronics Devices and Circuits, Microwave Engineering, Radar Engineering and Navigational Aids. Prof. Raju has been the best faculty performer in Andhra University with the performance index of $99.37 \%$.

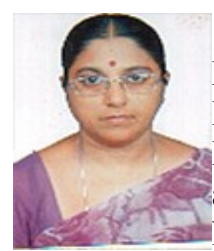

Dr. P.V.Sridevi received her B.Tech with distinction from Nagarjuna University, M.E from P.S.G.College of Technology and Ph.D. from Andhra University. She is a professor in Electronics and Communication Engineering department, Andhra University College of Engineering, Andhra University. She is having 25 years of teaching and research experience. Her areas of interest are Antennas, Electromagnetics and VLSI. She has published 20 papers in National and International Journals. 